\title{
Exploring Learners Contribution and Experience in Web-Based Collabo- rative Report Writing
}

\author{
Nur Syafiqa Aqiera @ Falecia Stephanie Clement ${ }^{1}$ and Kartini Abd Ghani ${ }^{2 *}$ \\ ${ }^{1}$ Politeknik Kuching Sarawak/Jabatan Pengajian Am, Malaysia \\ ${ }^{2}$ Universiti Malaysia Sarawak, 94300 Kota Samarahan, Sarawak, Malaysia
}

\begin{abstract}
Web 2.0 has given opportunities in letting students learn through active collaboration with and from their peers. The purpose of this study is to explore interactions that happens between learners, types of contributions made and learners' experience when collaborating in a Web-based context. The finding shows that the learners contribute in terms of adding, editing and deleting content and structure of their report. The learners' pattern of interaction shows that the learners with higher level of English proficiency are more dominant towards learners with lower level of proficiency. Students feedback shows that they are accepting the idea of writing collaboratively. Overall, the learners gave positive response towards the use of Google Docs in collaboratively completing their report writing project.
\end{abstract}

Keywords: Collaborative learning; English language learning

\section{INTRODUCTION}

As the language learning canvas changes with the emergence of Web 2.0 applications, more language teachers and educators are exploring the use of these tools in their class to facilitate their teaching process (Li \& Zhu, 2013). The tools in Web

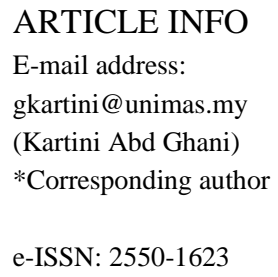

(C) Faculty of Cognitive Sciences and Human Development, Universiti Malaysia Sarawak
2.0 encompass arrays of "social technologies and tools that enable users to create, publish and share digital content within both new and existing social networks" (Judd, Kennedy \& Cropper, 2010). Due to the increasing popularity, more and more research has been done in relevant to collaborative writing projects. Previous research has been conducted on the student's online communication behaviour (Fischer, 2007), fluency and accuracy of online written products (Elola \& Oskoz, 2010) and perception of online peer-review of written task (Ge, 2011). 
Nur Syafiqa Aqiera @ Falecia Stephanie Clement and Kartini Abd Ghani

\section{BACKGROUND OF THE STUDY}

In learning English, learners are to learn four set of skills - reading, speaking, listening and writing - of which if mastered, can lead them to accomplish fluency in the language. Each of these skills is intertwined with one another as language mastery can only be achieved when the learners are able to perform or use these skills interchangeably while performing a language-based task (Powers, 2010). Among these skills, writing is dubbed as the hardest skill, even for the native speakers as it requires a vast knowledge of vocabulary and language rules and structures (Aydoğan \& Akbarov, 2014).

However in Malaysia, exposure to English language may not be sufficient due to the limited use of the language in the learners' environment (Ahmad \& Jusoff, 2009).Being said, language fluency is not easily achieved if the learners' practical uses of the language are confined only in the English classroom (Thirusanku \& Md Yunus, 2014).

In weaving the usage of Web 2.0 tools in their language class, language teachers are implementing collaborative learning in facilitating their lesson. Coined by Vygotsky in social learning theory, collaborative learning is an important method that entails learners to work collectively in discussing, sharing and giving meaning to the knowledge presented to them (Oxford, 1997). The crucial aspect in any collaboration is mutual understanding of the whole process in order to achieve the final goal of the collaboration. The learners then need to internalise the learning process to match their schemata in order to use the knowledge independently (Turuk, 2008).

In collaborative learning, learners are presented with the chance to develop their critical thinking skills in deducing information and acquiring deep understanding of their knowledge of the world (Lowyck \& Poysa, 2001). Knowledge sharing, which is an important part of collaborative learning process can lead to the coconstruction of shared mental model among the learners (Dalkir, 2005, Lipponen, 2002, Scardamalia \& Bereiter, 2006).

As stated earlier, writing is the hardest skill to be mastered. Language teachers now are presented with diverse tool which can be used in teaching writing to the students. The availability of tools such as blogs, Wikis and online document processors can be seen as a way to encourage students to write collaboratively together.

Collaborative writing involves the process of co-constructing ideas which in turn will encourage reflective and critical thinking (Elola \& Oskos, 2010). Elola and Oskos's study shows that there is a direct link between language fluency and the text content. Through collaboration with their peer, the students will be engaging in the process of rewriting, retuning and improving their versions of ideas to fit their peers' idea. This eventually led the students to think and reassess their ideas to create a mutually agreed text.

However, previous studies done in collaborative writing are focusing more into students' attitude and scrutinizing of the endproduct as opposed to evaluating the 
nature of the collaboration process when students are working together (Wen, Looi $\&$ Chen, 2015).

\section{Problem Statement}

This study is conducted to further add to the literature of web-based collaborative writing in Malaysia. This study's overarching theme is to explore the effectiveness of using web-based collaborative writing in a second-language classroom. As most of the current studies that examines collaborative writing in a second-language setting focus more on the end product in terms of its quality, fluency and accuracy, there is a need to look into the process of collaboration to further understand the learners concerns and experience. Even though the end product is the graded task, it is crucial to identify if students learn new knowledge through the collaborative writing process and from their group members

\section{Research Objectives}

Thus, the study aims to:

i. Explore students' contribution in the collaborative report writing process.

ii. Explore students' collaborative report writing experience using Google Docs.

\section{METHODOLOGY}

This study employs a case study research design which aims to explore the students' contributions and experience while using a web-based collaboration tool for collaborative report writing in a naturalistic setting. A public technical institution in Sarawak was selected as the venue for the study. The duration of the study was for four months, which is equivalent to one semester at a Polytechnic institution. In this study, one of the assessments of the English course is conducted collaboratively online as opposed to the usual practice of face-to-face collaboration.

\section{Population and Sample}

For this study, 20 students who enrolled in Communicative English 3 class participated in the research. They were chosen through purposive sampling and were divided into 5 groups each comprises of 4 students. The respondents' results for their previous Communicative English 2 ranging from $\mathrm{A}+$ to $\mathrm{C}+$.

\section{Instrument}

The primary data collection method in this study is the automatically recorded editing data saved through Google Docs online. From the recorded history, the respondents' participation and contribution can be analysed. Additionally, the data can also give insight as to determining the assumed or assigned role for each of the respondents.

A questionnaire was given at the end of the session to further strengthen the data obtained in the primary data collection method as the direct responses from the respondents can be triangulated with the main data to further enrich the data analysis. The questionnaire was adopted from Zhou, Simpson and Domizi (2012). This is because the questions used in their research were similar to the learning culture and environment in Polytechnic.

\section{Data Collection and Analysis}


Data collected were analysed as soon as the students completed their Mini Project presentation during lecture hours. An open-ended survey will be given to the students to explore the learners experience in using Google Docs to collaboratively write their report. Data collected from the open-ended survey will be triangulated with the recorded history of the collaboration process as recorded by Google Docs. Data analysis in qualitative research is complex and required attention to detail.

As the survey is an open-ended survey, the researcher need to analyse every response from the students and created a coding system to analyse the responses. Coding was done in terms of analysing the data using three flows of analysis namely, data reduction, data display and conclusion drawing (Miles \& Huberman, 1994). Data reduction is a process involving simplification and transformation of the responses. Data display on the other hand, needs the researcher to group the responses based on themes that emerges while the third analysis is where the data was then concluded. This however is not a straightforward process as several similar themes might crop out and the students' responses might fall into several themes at once.

\section{FINDINGS AND DISCUSSION}

This study's first objective is to find out the learner's contribution in the collaborative report writing process. Upon analysis, it is realised that the process of collaborative writing is not as straight forward as "the joint production of co-authoring of a text by two or more learners" as defined by Storch (2011). The report writing process undergone a complex process that requires the learners to negotiate, and restructure their understanding of a certain topic.

\section{Research objective 1- Learner's contri- bution in the collaborative report writ- ing process}

Learners' contributions were analysed into several categories based on the automatically saved revision after every editing done to the online document in Google Docs. These editing revisions are made available in the 'File - See Revision History'. The revision history is not editable but each revision can be restored. From the analysis, the contributions can be collectively grouped into two themes.

In the collaborative report writing process, the learners' contributions were themed as format or structure contribution and content contribution. Format contribution refers to the changes made to the numbering, labelling and structure of the report. The reports structure were added, edited and deleted over the course of writing collaboratively. The changes made to the text, tables, graphs or page includes the labelling, numbering, resizing, and spacing. These format contributions were done throughout the writing process for some groups while the other groups only did it towards the end of the writing process. 
Nur Syafiqa Aqiera @ Falecia Stephanie Clement and Kartini Abd Ghani

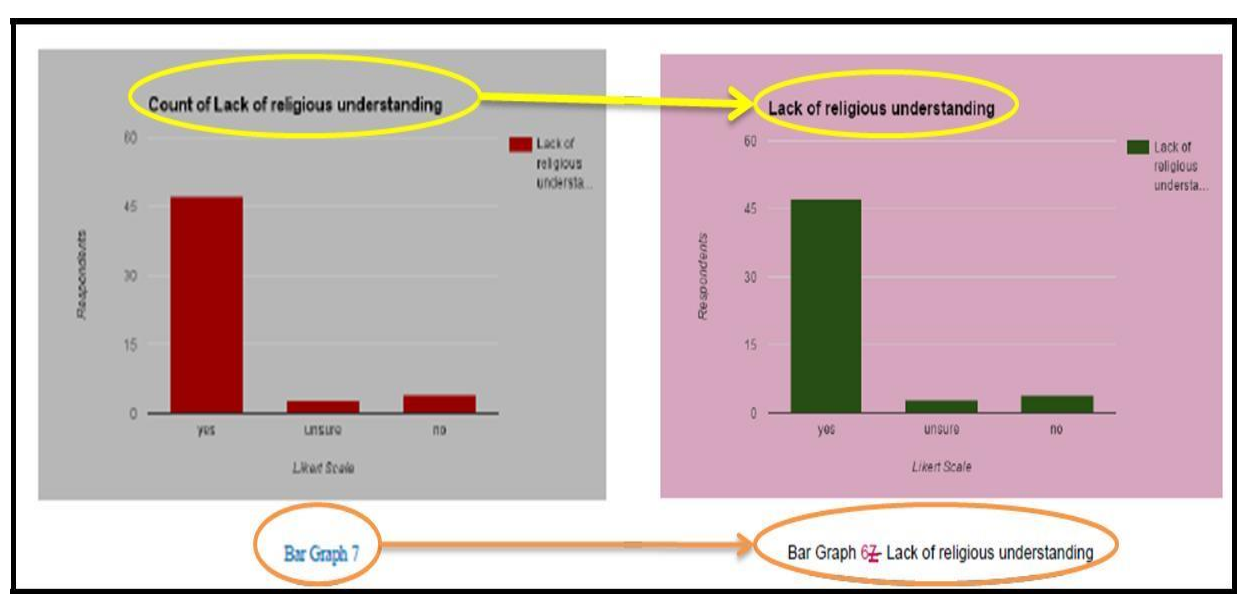

Figure 1: Changes in labelling

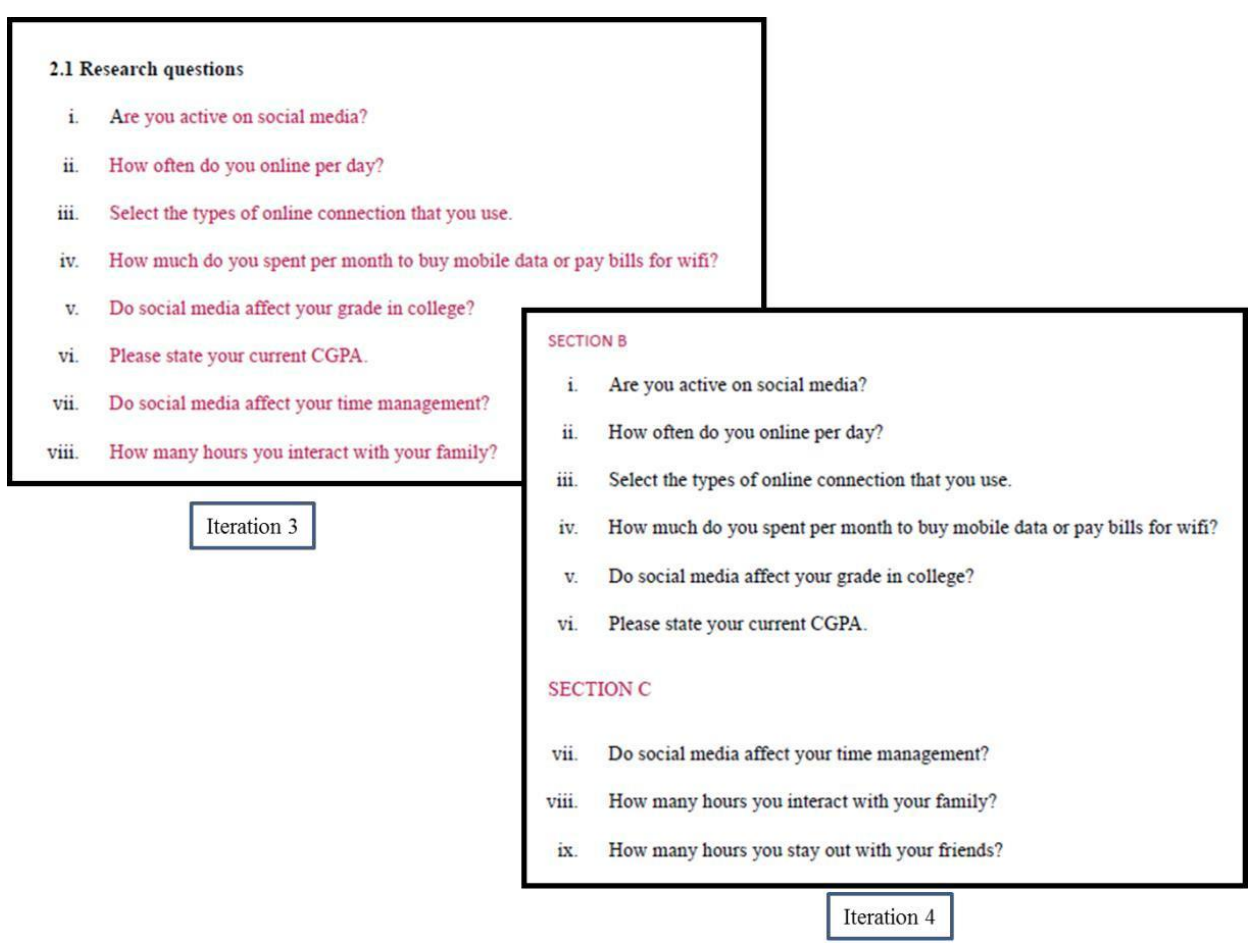

Figure 2: Structure contribution in Iteration4

Figure 1 shows an example of format contribution from Group 2. On the left is the original labelling done by the one of their group member earlier in the 3rd iteration and on the right is the changes done to the labelling by other group member in the 14th iteration which is the last editing iteration done by the whole group.

Figure 2 shows an example of structure addition done in Iteration 4 . The student added the research questions in a long list in Iteration 3. In Iteration 4, she divided 
the research questions into 2 separate sections.

The structure contribution refers to the non-language changes made by the learners in the document. From the analysis, in all the groups, majority of the learners did this contribution regardless of their level of English proficiency. Similar to the findings of Kessler, Bikowski and Boggs (2012), the learners did not wait until the end of their report to change the structure of their report, but they did it throughout the writing process. This is perhaps due to the ease of use of the structural and formatting tools that are made available in the online collaboration platform.

This is evidenced from the survey where the students stated that they think GoogleDocs is a useful tool for learning as it "(makes it) easy for student to edit the formatting of their work", "easy to use when want to change graphs because can automatic create one" and "can make me see what other member change to my part from the history and colour of my parts". This is supporting the findings by $\mathrm{Chu}$ and Kennedy (2011) where in their report the learners too commented on the ease of use of online-based collaborative learning, but in this study, privacy and formatting ability of the tool is not a concern for the learners.

The second contribution manifested in the findings is content contribution. From the analysis, there are three types of content contribution performed by the learners in the collaborative writing process. The first type of content contribution is the adding of the content. Figure 3 shows the addition of contents done in Iteration 2. In Main Page, one student added content in a sub-chapter in chapter 2 of the report. She only added 1 research statement or aim and did not add anything to it in Iteration 1 . In Iteration 2, another student added the second research statement or aim. The reason for the addition of the content is due to the requirement of the task which require the learners to have two research statements or aims.

The second content contribution is the editing of the content. Editing in the context of this study has been divided to four forms. The first editing form is editing content that do not change the meaning of the previous content and the second form is editing content that gives a new meaning to the content. The third form of editing contribution is the changes made to the sentence structure and the grammatical mistakes made in and the last form of editing is correcting the spelling mistakes in the report. Same as the first contribution, majority of the learners only edit their own content while only some played an active role in editing others content.

Based on Figure 4, one student added the thesis statement for their report in Iteration 9. When composing, she used the abbreviation of 'PKS' instead of the full name of the institution. In Iteration 12, another student noticed this and edited all the abbreviation to its full name 'Polytechnic Kuching Sarawak'. In addition to the editing, she also added some content to the thesis statement.

The last type of contribution is the deletion of the content made either by the 
group member themselves or other group members. The deletion was done mostly by the most proficient group members in the group.

In Iteration 12, as shown in Figure 5 above, a member of the group added content to one of the pie charts in their report findings. Later in Iteration 14, she deleted her earlier content and composed a new explanation for the pie chart. Upon close observation, she did the changes to her own content as she realised that the data in her earlier explanation were inaccurate.

The content contributions were made not only to their own content but also, for some learners, onto other member's content. The contributions made were not only restricted to spelling mistakes but also to the grammatical, choice of words

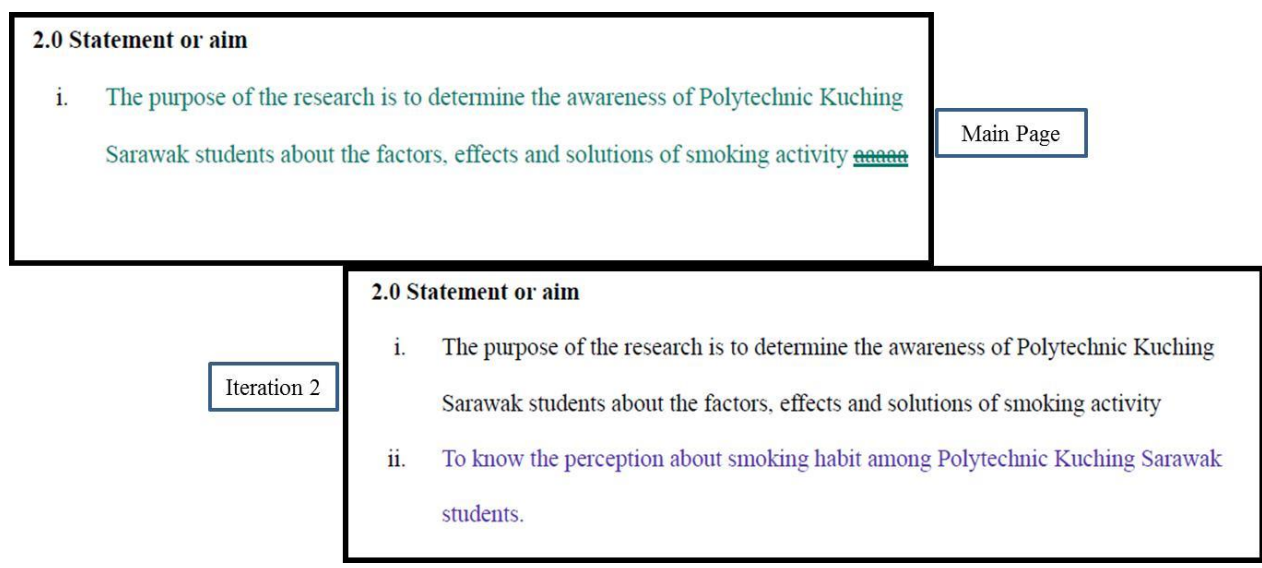

Figure 3. Adding of contents in Iteration 2

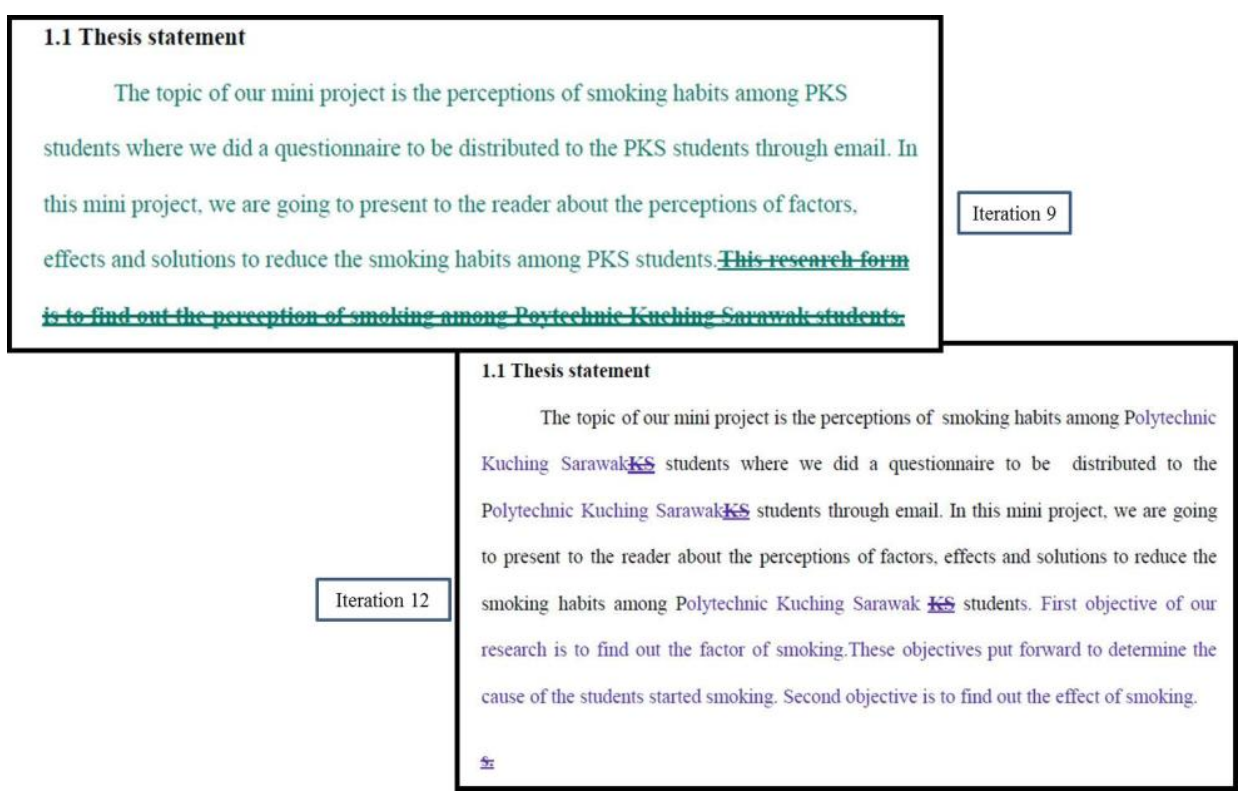

Figure 4. Editing of contents in Iteration 12 
Nur Syafiqa Aqiera @ Falecia Stephanie Clement and Kartini Abd Ghani

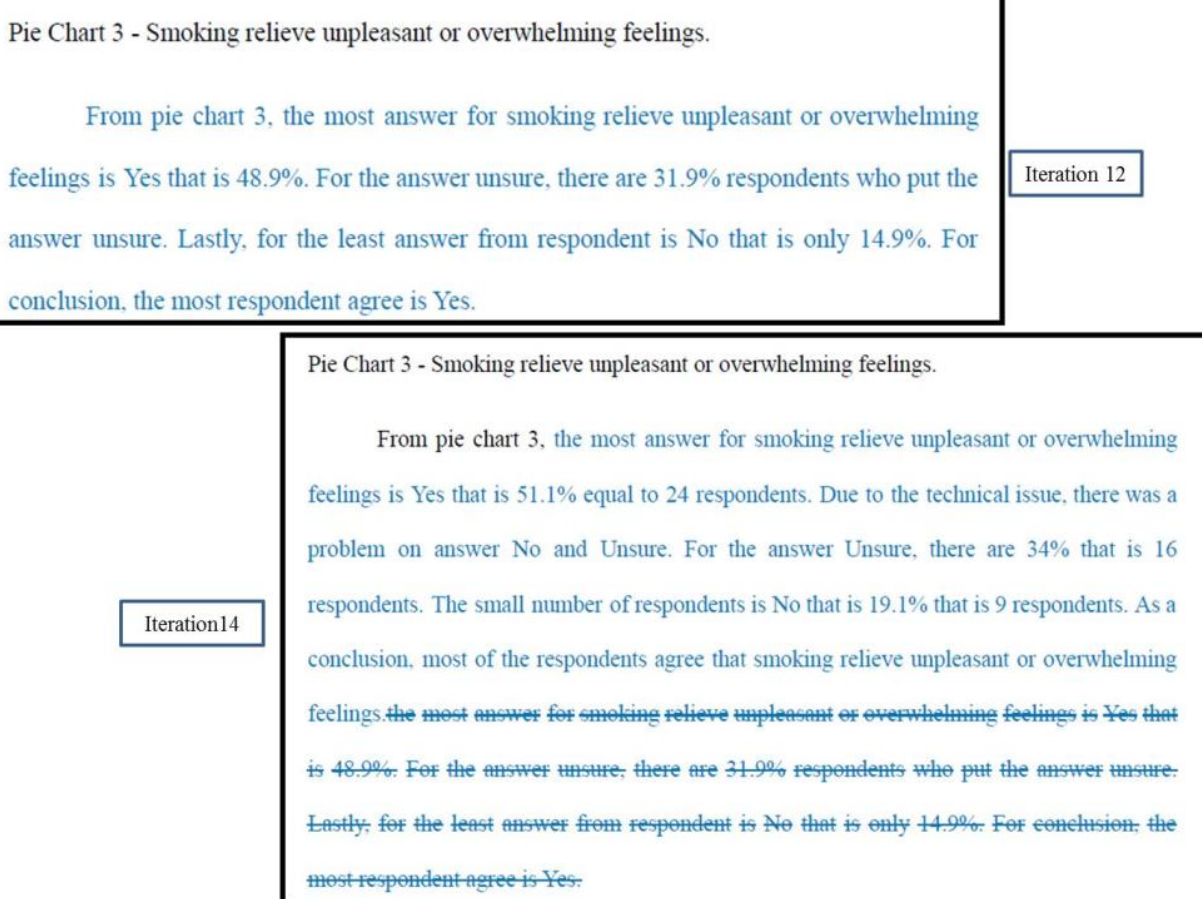

Figure 5: Deletion of content in Iteration 14

and sentence structure mistakes made by their group members which is consistent to Elola and Oskos (2010) in which the produced writings are more accurate and fluent.

From the five groups that were analysed, all of the learners participate by contributing to the creation of the report chapters and sub-units. While only some learners add to other group members content, most prefer to only add to their own previous content. Even though all the learners did this contribution, not all of the contributions done are of quality as expected by their other group members. There are several learners who actively and boldly took charge and heavily edited or deleted contents that are deemed as inaccurate.

As explained earlier in the study, the learners have different level of English proficiency. Although it did not have much influence in structure contribution, it is a different case for content contribution. The learners are more aware of their language proficiency and that hindered some of the learners to participate actively in the collaborative writing process. Although the idea behind the collaboration process as stated by Vygotsky (1978) was to encourage the learners to help each other in the process of writing, the writing process ends up to be more cooperative rather than collaborative for some of the groups. This is clearly illustrated in Group 5 where the learners seem to have designated parts of the document to each of the members. Their survey also supported this as most of them stated that their group are 'independent' or 'completely independent' when asked about the level of collaboration of their team work. There is only one group member 
who stated that the group completely collaborated in the writing process. This indicates that she might be the appointed leader for the group and she felt that they all collaborated because all the members did their parts in the writing process.

For the other groups, the pattern from the content contribution shows similar result as $\mathrm{Ge}$ (2010) in which the more fluent and competent learners dominates or contributed more in the writing process as compared to the other members and the learners with lower English proficiency who lost their confidence in the writing process. This might be the case as there are a few learners cease editing the content in their documents when their content were either edited heavily or deleted by the other group members.

Evidence form the analysis also shows that here are several types of interactions that emerge from the collaborative writing report process. The learners' interaction during the collaborative writing progress are categorised into three categories. The first category is the dominant or authoritative interaction. The learner that falls under this category usually will assume the role as the leader. However, in this report writing project, it is unclear if the learners have mutually appointed the leader for their group. The learners' interactions and collaboration contributions are the main indicator in the process of identifying the dominant member. This type of member tends to overpower the writing process by actively editing and deleting content typed by the other group members. Beside from that, the other members are reluctant or avoid editing or delete with the dominant member's content.

An example of a dominant interaction is shown in Figure 6. Ikhwan, coded in purple takes charge of the group's writing process. He did majority of the changes in the iterations. His authoritative side is very much displayed in the changes that he did as he did a lot of deleting in other member's content but the other's did not delete any of his.

The second category is the supporting or democracy member(s). This type of group member can be more than 1 in a group since there are 4 members in the collaborative report writing project. The supporting or democracy group member is usually relaxed and not as bold as the dominant member in dealing with the report progress. They are more to assisting the other group members rather than outright editing or deleting the members' contents. Also, from the analysis, some of the supporting members do no edit or change their group members part but only highlighting the mistakes so that the original contributor recheck their work.

From Figure 7, it can be observed that the interaction and contribution pattern between Group 4 members are very different from the other groups. The pattern shows that there is no dominant member controlling the report writing process. All the group members are helping each other out without dismissing any of their group members. In term of interaction, this group has the ideal interaction pattern. 
Nur Syafiqa Aqiera @ Falecia Stephanie Clement and Kartini Abd Ghani

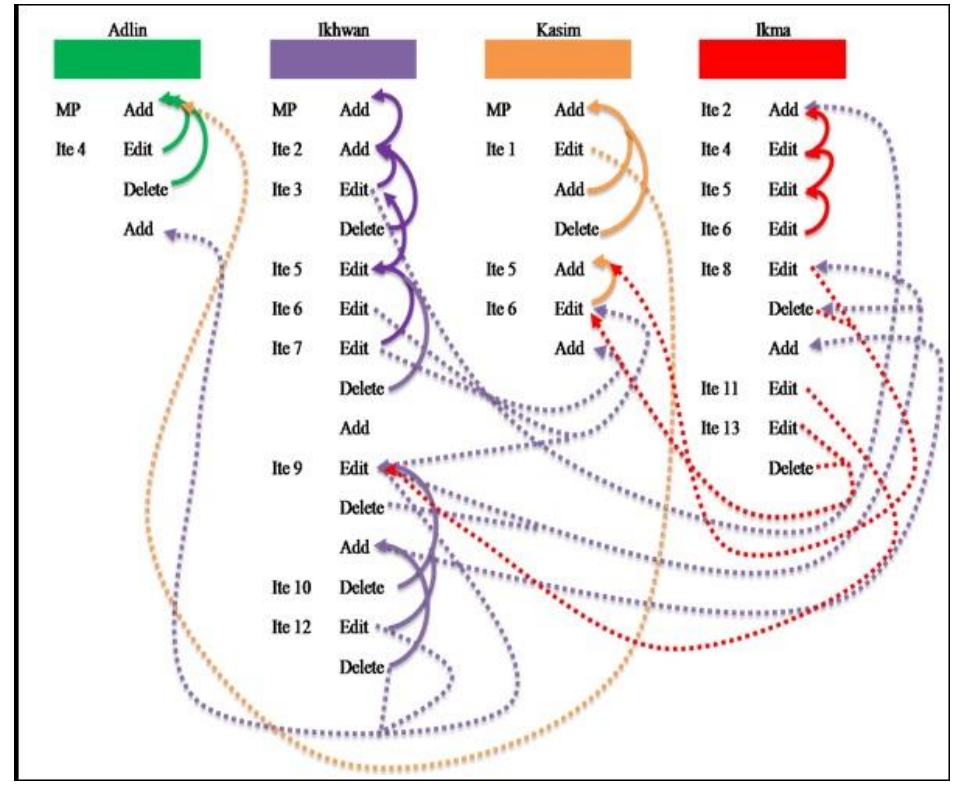

Figure 6: Group 1 Interaction and collaboration contribution pattern

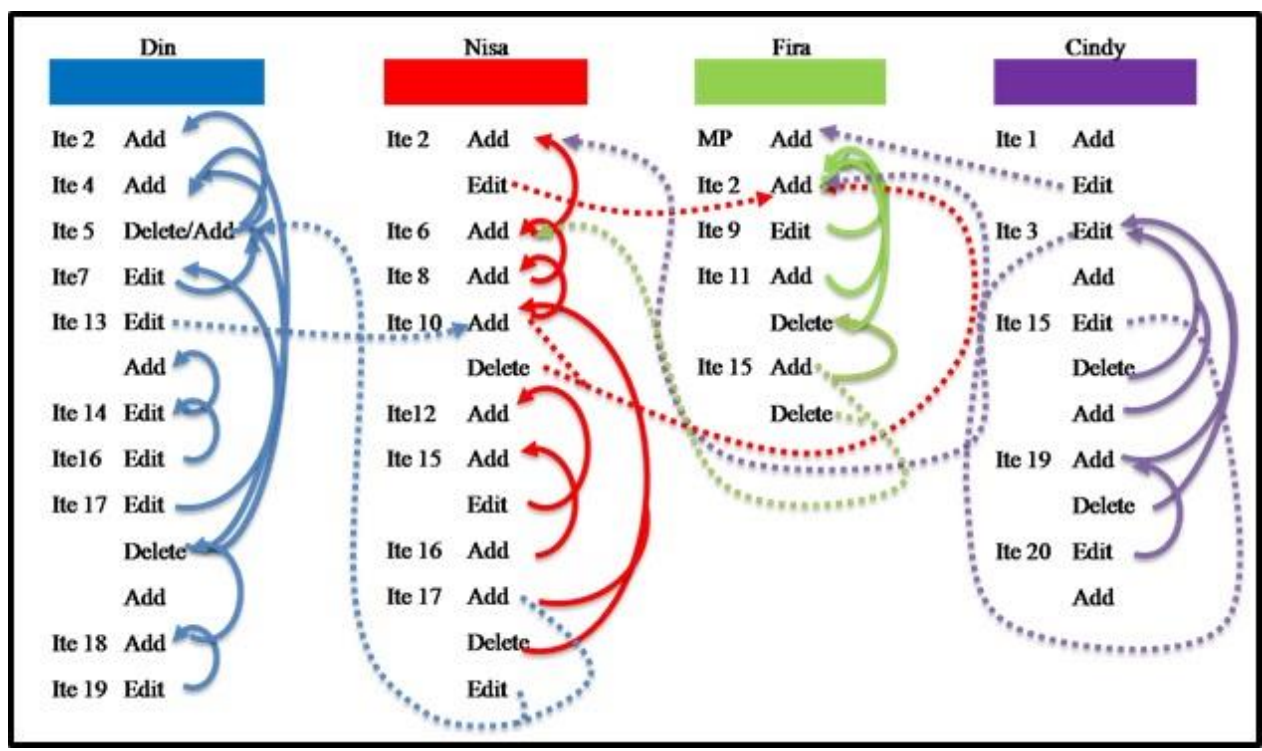

Figure 7: Group 4 Interaction and collaboration contribution pattern

The last pattern of interaction is the withdrawn or passive member. There are several reasons as to why this pattern emerges. First is the learners are lacking fluency in the language, hence the minimal contribution. Second might be the result of the aggressive actions taken by the dominant member, and cause the others to give up or simply become passive. Passive members are indicated in the analysis as the member that contributes the least in the collaborative report writing process. It is to be noted that even if the group member is passive, they may have good command of the language. 
As can be seen in Figure 8, the interaction patterns among the group members were purely disconnected. There were no indications in the iterations that the members were collaborating online in the report writing process. The patterns suggested that the team members might have allocated or distributed the sections amongst themselves prior to the writing process. Despite the rich content contribution, the members are totally focusing only on their own content and made no attempt to interfere or edit other learners' contents.

\section{Research objective 2 - Learners' expe- rience in using Google Docs}

This study's second objective is to find out the learner's collaborative report writing experience using Google Docs. After the learners completed their collaborative report writing process, they were given a set of survey to evaluate their experience in using Google Docs. 19 learners answered the survey because one of the learners dropped out of the institution during the writing process.

From the answers given, it can be assumed that the learners' idea of their group's performance is not mutually the same. Overall, majority of the learners rated their group performance as 'good' or 'very good', a group member from Group 1 stated that their group performance is 'bad'. It is found out that, he experienced negative collaboration through the use of Google Docs as he is the main contributor to the writing process. One of his group members dropped out and the rest of the group members rely heavily on him to complete the task.

When asked to describe their experience in using Google Docs, all the learners responded positively. They unanimously commended on the ease of use of the platform and the convenience of not having to meet up in campus to do their writing project. Some of the learners also stated that

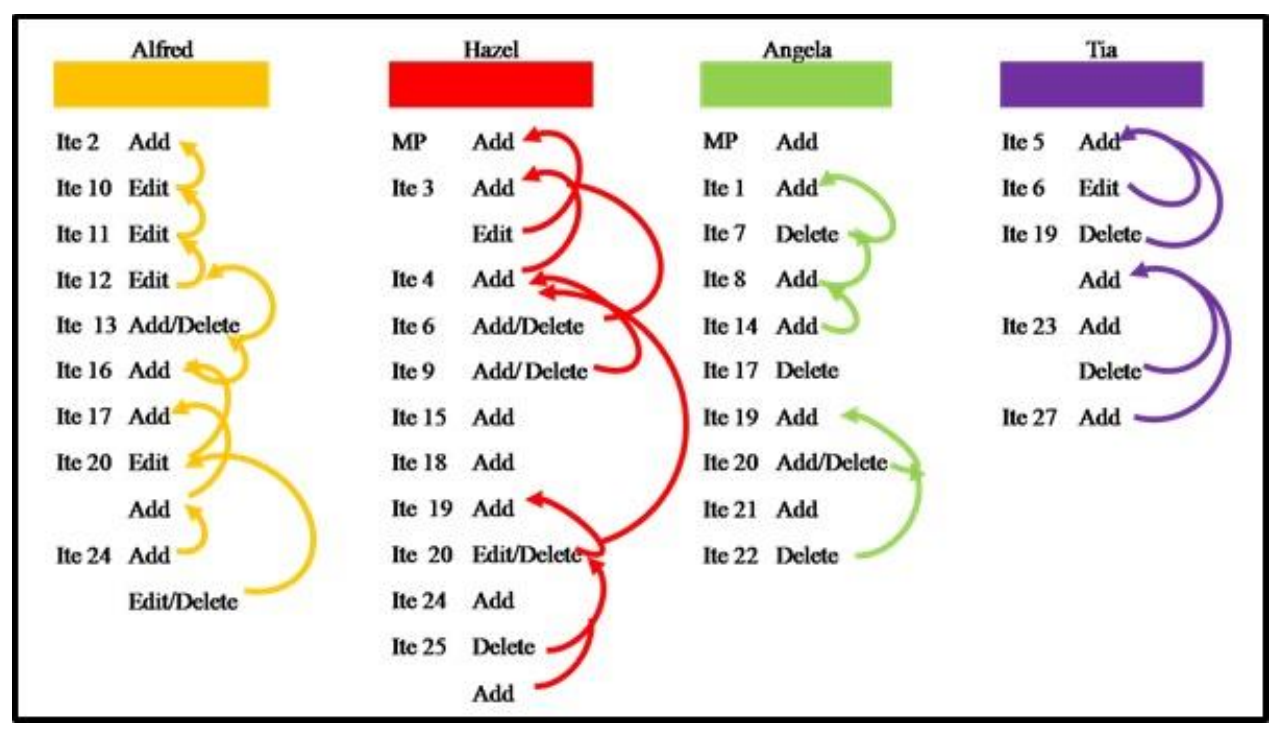

Figure 8: Group 5 Interaction and collaboration contribution pattern 
the use of Google Docs improve their team efficiency as they can directly comment and edit the documents together instead of passing it around in a flash drive that makes them prone to virus infections.

However, as expected, majority of the learners stated that the internet connectivity was the main downfall in using Google Docs. A learner from Group 2 said "No WiFi, no Google Docs" and another learner from Group 4 said “...but the problem is internet connection. We have to stay (up) at night to do a task". This finding is similar to a study done by Kenan, Elzalwi, Pislaru and Restoum (2015), in which their respondents also highlighted that the internet bandwidth and connectivity significantly influence their collaborative learning process.

In asking about if the learners would like to use the tool in the future, all of them said 'yes' but with exception that the institution provides better wireless internet connection. Apart from that, they would like to use Google Docs again in the future due to its cost effectiveness whereby they can save on the cost of printing since colour printing costs them a lot of money. They too save on time and can directly send the completed documents to the lecturer.

\section{CONCLUSION AND RECOMMEN-} DATION

This finding of this study shows that the learners did contribute in terms of adding, editing and deleting content and structure of their report. The learners' pattern of Interaction shows that the learners with higher level of English proficiency are more dominant towards learners with lower level of proficiency. Overall, the learners gave positive response towards the use of Google Docs in collaboratively completing their report writing project.

\section{Limitation of study}

In analysing the data obtained from the Google Docs history and the open-ended survey, there are several issues that most probably have some impact on the learners' collaboration.

\section{Internet access}

The first issue is the access to the internet. From the survey, most of the learners' highlighted this issue as the main factor that might hamper their mood to use this platform in the future. Even though the learners do have access to the institution's wireless connection when they are in the campus, they lack the time to complete the task due to their packed timetable. The learners do have their own mobile internet package, but with the limited data connection, they are forced to do their work after midnight as the data connection plans are much cheaper.

\section{Teamwork}

All the group members have self-select their own group members to minimise the awkwardness and free loader in their group. This method however, did not hinder some of the members to contribute less in the group. This is as evidenced in group 1 where Ikhwan indicated that there is a member in their group that did not 
give much effort to contribute in the report writing process. Perhaps that is the reason as to why Ikhwan is being authoritative throughout the report writing process. Besides that, as the collaborative writing process is an out-of-class activity, the learners have limited face-to-face guidance or sessions with the lecturer to discuss the progress of their report. This might be another factor that contributes to the members not participating actively in the project as there is no higher authority to monitor and intervene in their report writing process.

\section{Familiarity of genre and language pro- ficiency}

The learners do write reports for their other courses, but the structure of a business report is very much different from the ones that they have to write for DUE5012 course. For their business report, the learners only presented their profit and losses as everything is factual. But for DUE5012 course, the learners need to conduct a study on an issue that they are interested in. They have to find out their research objective and gather data prior to writing the report. In their report writing, learners are to present their findings in form of charts and graphs using specific terms taught throughout their class tutorial.

Besides that, the learners use Bahasa Malaysia to write their business report so their level of English language proficiency might hinders them from thoroughly expressing themselves and their ideas in the project. Although this study is on exploring the contribution that they made, the unfamiliarity of report writing and their level of proficiency do have some influence on the learners contribution and interaction patterns.

\section{Future areas for the research}

For future research in the area of online collaborative writing, it is important that the key issues of this study are to be addressed for a more thorough and complete findings. The main concern for future research is that to make sure that the learners fully understand the difference between cooperation and collaborative learning. Although in this study, the learners are told the differences, some of them cooperated instead of collaborate in the writing process. Perhaps, in future, the researcher should find a new approach or method to promote and ensure that collaborative learning happens.

As this study focuses on the documented history of the learners contribution while using Google Docs, there is a lack of insight on the face-to-face interactions among the learners. In future research, may be instead of doing the on-line collaborative writing process an out-of-class activity, the research might want to allocate a specific time or employ another method such as reflective journals where the respondents face-to-face interactions can be captured, documented and analysed.

The level of proficiency for the learners in this study varies due to limited number of respondents agreeing to be a part of the study. This is a drawback as the learners English proficiency can be the underlying 
factor as to the reason the collaborative writing process for some groups were not successful. For future research, the researcher might want to find respondents that have similar level of proficiency for each group. The research also can looked into the differences in the interaction pattern between the group that have high level of proficiency and the group with lower level of English proficiency.

This study has revealed that in collaborative writing setting, learners interact and contributed in several ways unique to each group. While most of the learners do embrace the concept of working together, some chose to participate less and remain passive throughout the writing process. Nevertheless, all the learners appreciate and adore the idea of conducting their written project online despite the experience that they have in conducting this collaborative report writing project.

\section{ACKNOWLEDGEMENTS}

The authors are very grateful for the cooperation extended by participants and administrator of the technical institution in Sarawak.

\section{REFERENCES}

Ahmad, B.H., \& Jusoff, K. (2009).Teachers' Code-Switching in Classroom Instructions for Low English Proficient Learners. English Language Teaching, 2(2).

Aydoğan, H., \& Akbarov, A. A. (2014). The Four Basic Language Skills, Whole Language \& Intergrated Skill Approach in Mainstream
University Classrooms in Turkey. Mediterranean Journal of Social Sciences, 5(9), 672.

Chu, S.K.W. \& Kennedy, D.M. (2011).Using online collaborative tools for groups to co-construct knowledge. Online Information Review, 35(4).

Dalkir, K. (2005), Knowledge Management in Theory and Practice, Elsevier, Oxford.

Elola, I., \& Oskoz, A. (2010). Collaborative writing: Fostering foreign language and writing conventions development. Language Learning \& Technology, 14(3), 51-71.

Ge, Z. G. (2011) Exploring e-learners' perceptions of net-based peer-reviewed English writing.International Journal Computer-Supported.Collaborative Learning. 6 (1), 75-91.

Judd, T., Kennedy, G., \& Cropper, S. (2010). Using wikis for collaborative learning: Assessingcollaboration through contribution.Australasian Journal of Educational Technology, 26(3), 341-354.

Kenan, T., Elzawi, A., Pislaru, C., \& Restoum, M. (2015). A Study on the Impact of ICT on Collaborative Learning Processes in Libyan Higher Education. International Journal of Learning, Teaching and Educational Research, 10(1), 172190.

Kessler, G., Bikowski, D., \& Boggs, J. (2012). Collaborative writing among second language learners in academic web-based projects.Language Learning \& Technology, 16(1), 91-109. 
Nur Syafiqa Aqiera @ Falecia Stephanie Clement and Kartini Abd Ghani

Lipponen, L. (2002, January). Exploring foundations for computer-supported collaborative learning. In Proceedings of the conference on computer support for collaborative learning: Foundations for a CSCL community (pp. 72-81). International Society of the Learning Sciences.

Lowyck, J., \& Pöysä, J. (2001). Design of collaborative learning environments. Computers in human behavior, 17(5), 507-516.

Miles, M. B., \& Huberman, A. M. (1994). Qualitative data analysis: An expanded sourcebook. Sage.

Oxford, R. L. (1997). Cooperative learning, collaborative learning, and interaction: Three communicative strands in the language classroom. The Modern Language Journal, 81(4), 443-456.

Powers, D. E. (2010). The case for a comprehensive, four-skills assessment of English-language proficiency. $R$ \& D Connections, 14.

Scardamalia, M., \& Bereiter, C. (2006). Knowledge building. The Cambridge.
Storch, N. (2011). Collaborative Writing in L2 Contexts: Processes, Outcomes, and Future Directions. Annual Review of Applied Linguistics, 31(1), 275-288.

Thirusanku, J., \& Yunus, M. M. (2014).Status of English in Malaysia.Asian Social Science, 10(14), 254.

Turuk, M. C. (2008). The relevance and implications of Vygotsky's sociocultural theory in the second language classroom. ARECLS, 5, 244262.

Vygotsky, L. S. (1978). Mind in society. Cambridge, MA: Harvard University Press.

Wen, Y., Looi, C \& Chen, W. (2015).Appropriation of a representational tool in a second-language classroom.International Journal Computer-Supported.Collaborative Learning.10(1).

Zhou, W., Simpson, E., \& Domizi, D. P. (2012). Google Docs in an Out-ofClass Collaborative Writing Activity. International Journal of Teaching and Learning in Higher Education, 24(3), 359-375. 